\title{
Identifikasi Batuan Pondasi Candi (Andesit) di Bawah Permukaan Sekitar Candi Badut dengan Metode Geolistrik Resistivitas
}

\author{
Ahmad Luthfin ${ }^{1, *}$, Husni Cahyadi $\mathrm{K}^{2}$, dan Jufri ${ }^{3}$ \\ ${ }^{1}$ Jurusan Fisika, Fakultas SAINTEK, UIN , Malang \\ ${ }^{2}$ Jurusan Tadris Fisika, Fakultas tarbiyah dan ilmu keguruan, IAIN Tulungagung \\ ${ }^{3}$ Jurusan SAINS, Fakultas Keguruan \& Ilmu Pendidikan, Universitas Darussalam Ambon \\ "Email: ahmadluthfin@fis.uin-malang.ac.id
}

\begin{abstract}
The Badut temple site is predicted to have a foundation that extends a square to support the core building of the temple so that it does not collapse. Based on the physical shape of the upper part, the site of Badut Temple is incomplete, so it is possible that there are rock remains that fulfill the full function of the temple still buried. Based on these assumptions, this research activity aims to identify the foundation rock of Badut Temple and the andesite rocks buried around the temple building. The method used is the resistivity geoelectric method, this method is often used to investigate the subsurface of the earth, because the resistivity geoelectric method can determine the type and structure of rock without digging, only based on the distribution of subsurface resistivity. The instrument used was a complete OYYO MC OHM Resisvitimeter and electrodes. The configuration for the electrode array uses the Wenner configuration because this configuration is considered capable of obtaining more precise data compared to other configurations. Based on the results of research on the overall interpolation of trajectories 1,2,3 and 4 with the geoelectric resistivity method using the Wenner configuration, it can be seen that the temple foundation rock (andesite) is at a depth of $0.5-1.5$ $\mathrm{m}$, which is the rock with the largest resistivity value compared Other rocks with rock resistivity values ranging from $33.87 \Omega \mathrm{m}-66.8 \Omega \mathrm{m}$, while at a depth of $1.51 \mathrm{~m}-7.91 \mathrm{~m}$ consisting of watery silt soil and sandy silt soil, no temple rocks (andesite) were found buried in the ground.
\end{abstract}

Keywords: Foundation, temple rock, geoelectric resistivity

\section{ABSTRAK}

Situs Candi Badut diprediksi memiliki pondasi yang melebar persegi empat untuk menopang bangunan inti candi agar tidak ambles. Situs Candi Badut berdasarkan bentuk fisik bagian atas, susunannya kurang lengkap, sehingga dimungkinkan masih terdapat sisa-sisa batuan yang memenuhi fungsi utuh dari candi tersebut masih terkubur. Berdasarkan asumsi tersebut maka kegiatan penelitian kali bertujuan untuk mengindentifikasi batuan pondasi Candi Badut dan batuan andesit yang terkubur disekitar bangunan candi. Metode yang digunakan adalah metode geolistrik resistivitas, metode ini sering digunakan untuk melakukan investigasi bawah permukaan bumi, karena metode geolistrik resistivitas dapat menentukan jenis dan struktur batuan tanpa harus menggali, hanya berdasarkan sebaran resisitivitas dibawah permukaan. Alat yang digunakan adalah Resisvitimeter OYYO MC OHM lengkap beserta elektrodanya. Konfigurasi untuk susunan elektrodanya menggunakan konfigurasi wenner karena konfigurasi tersebut dianggap mampu memperoleh data yang lebih teliti dibandingkan dengan konfigurasi lainnya. Berdasarkan hasil penelitian pada keseluruhan interpolasi lintasan 1,2,3 dan 4 dengan metode geolistrik resistivitas menggunakan konfigurasi wenner dapat diketahui bahwa batuan pondasi candi (andesit) berada pada kedalaman 0,5-1,5 m,yang merupakan batuan dengan nilai 
resistivitas terbesar dibandingkan batuan yang lainnya dengan nilai resistivitas batuan kisaran antara 33,87 $\Omega \mathrm{m}-66,8 \Omega \mathrm{m}$, sedangkan pada kedalaman $1,51 \mathrm{~m}-7,91 \mathrm{~m}$ terdiri dari tanah lanau basah lembek dan tanah lanau, pasiran, tidak ditemukan batuan candi (andesit) yang terkubur didalam tanah.

Kata kunci: Pondasi, batuan candi, geolistrik resistivitas

\section{PENDAHULUAN}

Candi badut merupakan candi yang bercorak hindu tersusun dari batuan andesit yang terdapat di Propinsi Jawa Timur, tepatnya di Desa Karangbesuki Kecamatan Sukun, Kota Malang. Situs Candi Badut ketika dilaporkan pertamakali pada tahun 1921 M oleh Maureen Brecher, seorang pegawai VOC Belanda yang bekerja di Malang, masih merupakan gundukan bukit berbatu, pada tahun 1923-1925 M dibawah pengawasan B. De Haan dari purbakala Hindia Belanda pertama kali pemugaran dilakukan. selanjutnya pada tahun 1990-1993 M dilaksanakan pemugaran lebih lanjut oleh Kanwil Dekdikbud Suaka Peninggalan Sejarah dan Purbakala Jawa Timr, secara bertahap ${ }^{[1]}$.

Situs Candi Badut diprediksi memiliki pondasi yang melebar persegi empat untuk menopang bangunan inti candi agar tidak ambles. Seperti yang ditunjukkan pada gambar dibawah ini:

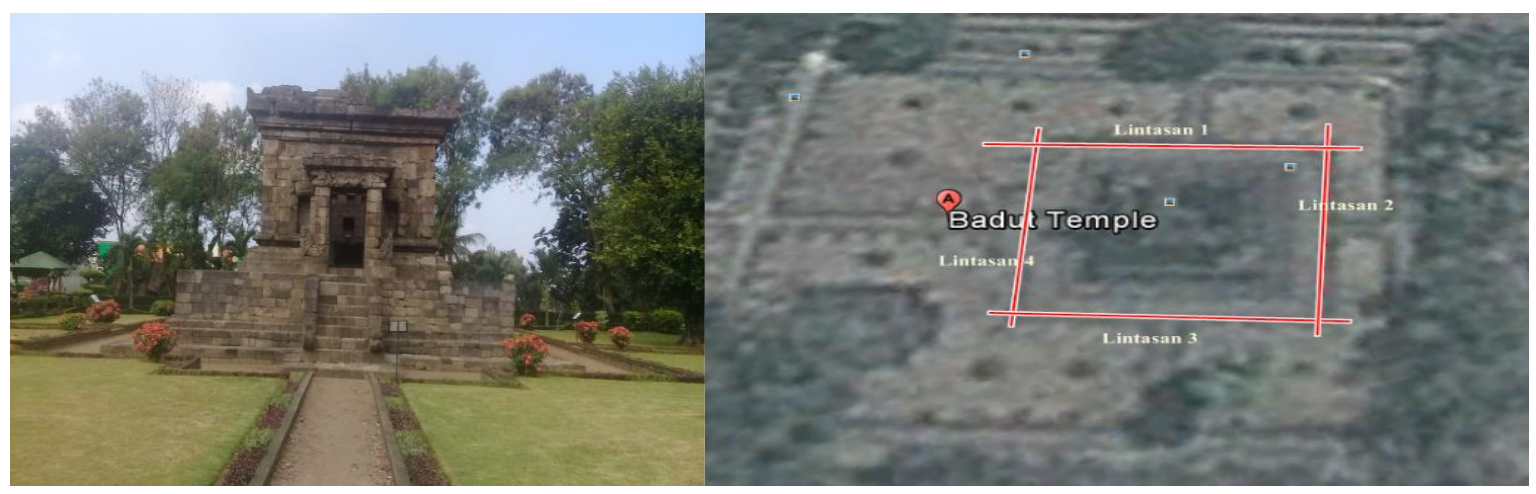

(a)

(b)

Gambar 1. (a) Foto candi badut Sekarang (b) Foto dari google earth area yang akan diukur

Berdasarkan gambar diatas untuk mendeteksi batuan pondasi candi dimungkinkan terdapat pada kedalaman 0m-2m. Berdasarkan gambar 1. (a) bentuk fisik bagian atas, susunannya kurang lengkap,ada beberapa batuan arca dewa yang sudah tidak ada. sehingga dimungkinkan masih terdapat sisa - sisa batuan yang memenuhi fungsi utuh dari candi tersebut masih terkubur. Walaupun dalam sejarah renovasinya pernah dilakukan penggalian dan ditemukan beberapa batuan candi tapi kemungkinan ada bagian - bagian tertentu belum dapat ditemukan. Adapun batuan candi yang sudah ditemukan tapi belum dilakukan pemugaran adalah sebagai berikut: 


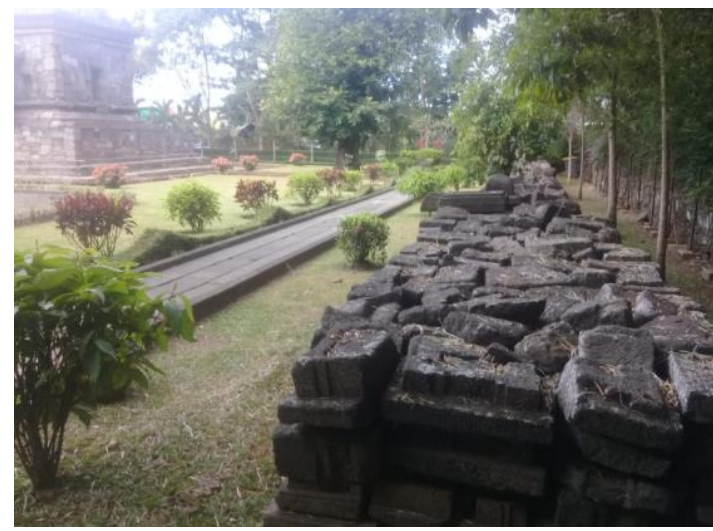

Gambar 2. Batuan candi yang telah ditemukan tapi belum dilakukan pemugaran

Dengan demikian, berdasarkan asumsi tersebut kegiatan penelitian untuk mengindentifikasi sturuktur bawah permukaan disekitar pondasi Candi Badut itu sangat penting dilakukan untuk mengetahui ada tidaknya batuan pondasi candi dan batuan andesit lainnya yang masih terkubur.

Berdasarkan proses pembentukannya, Batuan Andesit dikategorikan sebagai batuan beku ekstrusif yang memiliki kandungan silicon dioksida 57-63\% ${ }^{[2]}$. Batuan andesit biasa ditemukan pada aliran lava yang tercipta dari stratovolcano, pada area naiknya magma ke permukaan mengalami proses pendinginan yang cepat ${ }^{[3]}$. Andesit biasanya terletak di zona subduksi yang terbentuk setelah lempeng samudera meleleh disebabkan proses subduksi. Proses subduksi diakibatkan oleh pencairan di zona ini yang merupakan sumber magma, ketika sumber magma itu naik ke permukaanmenghasilkan andesit ${ }^{[4]}$. Nilai resistivitas batuan dipengaruhi oleh beberapa faktor diantaranya saturasi fluida, suhu, porosistas batuan dan salinitas. Batuan Andesit merupakan batuan yang memiliki sifat resistif dengan resistivitas yang relatif tinggi nilai sekitar $300 \Omega \mathrm{m}-600 \Omega \mathrm{m}^{[5,6]}$. Berdasarkan hasil penelitian yang dilakukan untuk identifikasi batuan andesit di Desa Pulosiri nilai tahanan jenis (resistivitas) batuan andesit didesa tersebut sebesar $212 \Omega \mathrm{m}-300 \Omega \mathrm{m}^{[7]}$. Pada data penelitian lainnya didapatkan nilai resistivitas batuan andesit $40 \Omega \mathrm{m}<\rho<250 \Omega \mathrm{m}^{[8]}$. Hal ini menunjukkan karakteristik batuan andesit sangat resistiv (bukan konduktor listrik yang baik), dengan nilai resistivitas bervariasi tergantung kondisi batuan andesit tersebut. Karakteristik batuan candi (andesit) sudah mengalami pelapukan dengan tingkat pelapukan batuan berbanding lurus dengan besarnya pori batuan yang disebabkan faktor iklim (hujan), jumlah feldspar, hornblenda serta kenaikan pori bagian dalam batuan. Mineral plagioklas yang menyusun batuan andesit umumnya berubah menjadi kaolin dan montmorilonit, sedangkan hornblenda dan piroksen berubah menjadi goetit dan hematit. Proses pelapukan meliputi oksidasi, hidrasi dan hidrolisis ${ }^{[9]}$. Sehingga memungkinkan batuan andesit candi memiliki karakteristik dan nilai reisitivitas yang berbeda dengan batuan andesit yang langsung didapatkan dari alam. Pada penelitian kali ini peneliti menggunakan metoda geolistrik reisitivitas, untuk mendapatkan kemungkinan adanya pondasi Candi Badut dan puing batuan candi yang terkubur.

\section{Metode Resistivitas}

Metode resistivitas merupakan salah satu metode geofisika yang mempelajari sifat aliran listrik di bawah permukaan bumi dan mendeteksinya di permukaan bumi berdasarkan sifat tahanan jenis lapisan batuan penyusun kerak bumi ${ }^{[10]}$. Metode ini dapat digunakan pada penentuan struktur pondasi bangunan, pendugaan potensi air bawah permukaan, eksplorasi panas bumi, eksplorasi mineral hingga pendugaan intrusi air laut dan limbah. Data yang diperoleh dari hasil pengukuran di lapangan adalah data akumulasi kondisi bawah 
permukaan. Metode geolistrik resistivitas sangat sering digunakan untuk melakukan investigasi bawah permukaan bumi, karena metode geolistrik resistivitas di dalam bumi dapat menentukan jenis dan struktur batuan ${ }^{[11]}$. Metode geofisika merupakan metode yang dapat memberikan informasi bawah permukaan tanpa harus menggali ${ }^{[12]}$.

Tujuan dari metode geolistrik adalah untuk menentukan sebaran resisitivitas dibawah permukaan $^{[13]}$. Prinsip dasar hukum fisika yang digunakan pada metode geolistrik resistivitas adalah hukum ohm dimana arus dialirkan kebawah permukaan melalui sebuah eletroda.

Adapun prinsip kerja dari metode ini dengan menginjekkan elektroda arus (AB) ke dalam bumi. Maka elektroda potensial akan mengukur beda potensial dari arus yang melewati bawah permukaan bumi, kemudian perhitungan resistivitas semu batuan dihitung dengan menggunakan hukum $\mathrm{Ohm}^{[14]}$.Persamaan hukum $\mathrm{Ohm}$ untuk arus yang mengalir kontinyu didalam medium di tunjukkan sebagai berikut ${ }^{[15]}$ :

$$
\begin{aligned}
& I=\sigma E \\
& E=-\nabla V \\
& I=-\sigma \nabla V \\
& \nabla \cdot J=0 \\
& \nabla \cdot(\sigma \nabla V)=0
\end{aligned}
$$

Dimana $\mathrm{J}$ adalah kerapatan arus $\left(\mathrm{A} / \mathrm{m}^{2}\right)$, $\mathrm{E}$ adalah medan listrik $(\mathrm{V} / \mathrm{m}), \sigma$ adalah konduktivitas, $\mathrm{V}$ adalah potensial listrik(V). Pemberlakuan syarat lapace pada persamaan diatas, kemudian hasilnya dimasukkan pada koordinat bola didapatkan:

$$
\nabla^{2} V=\frac{1}{r^{2}} \frac{\partial}{\partial r}\left(r^{2} \frac{\partial V}{\partial r}\right)+\frac{1}{r^{2} \sin \theta} \frac{\partial}{\partial \theta}\left(\sin \theta \frac{\partial V}{\partial \theta}\right)+\frac{1}{r^{2} \sin ^{2} \theta} \frac{\partial^{2} V}{\partial \emptyset^{2}}=0
$$

Untuk suku pertama pada persamaan (2) kami dapatkan persamaan sebagai berikut

$$
\begin{aligned}
& \frac{1}{r^{2}} \frac{\partial}{\partial r}\left(r^{2} \frac{\partial V}{\partial r}\right)=0 \\
& \frac{\partial}{\partial r}\left(r^{2} \frac{\partial V}{\partial r}\right)=0
\end{aligned}
$$

Sehingga konstanta untuk persamaan (3) diatas adalah

$$
\begin{aligned}
& r^{2} \frac{\partial V}{\partial r}=A \\
& V=-\frac{A}{r} \\
& A=-\frac{I \rho}{2 \pi}
\end{aligned}
$$

Dimana $\mathrm{r}$ adalah jari-jari (m), $\mathrm{V}$ adalah potensila listrik (volt), I adalah arus listrik (A), $\rho$ adalah nilai resistivitas batuan dalam $\Omega \mathrm{m}$, Adapun beda potensial antara $\mathrm{P}_{1}$ dan $\mathrm{P}_{2}$

$$
\nabla V=\frac{I \rho}{2 \pi}\left\{\left(\frac{1}{r_{1}}-\frac{1}{r_{2}}\right)-\left(\frac{1}{r_{a}}-\frac{1}{r_{4}}\right)\right\}
$$

Berdasarkan persamaan (4) tersebut diatas nantinya didapatakan faktor geometri k sebagai berikut: 


$$
k=\frac{2 \pi}{\left(\frac{1}{r_{1}}-\frac{1}{r_{2}}\right)-\left(\frac{1}{r_{3}}-\frac{1}{r_{4}}\right)}
$$

Sehingga didapatkan persamaan resistivitas sebagai berikut:

$$
\rho=\frac{\nabla V}{I} k=R k
$$

Dimana $\mathrm{R}$ adalah hambatan $\Omega$, metode resistivitas, memiliki berbagai macam konfigurasi elektroda. Adanya berbagai konfigurasi-konfigurasi elektroda tersebut menyebabkan pengaruh terhadap besar resistivitas, hal ini dikarenakan tiap-tiap konfigurasi memiliki faktor K yang berbeda berdasarkan susunan dari elektrodanya ${ }^{[16]}$. Susunan konfigurasi elektroda dibagi menjadi 2 (dua) tipe yaitu tipe sounding (1 dimensi) dan mapping (2 dimensi). Tipe sounding(1 dimensi) biasanya digunakan untuk identifikasi kontras resisitivitas secara vertikal, contoh : konfigurasi Wenner sounding dan Schlumberger. Sedangkan tipe mapping (2 dimensi) digunakan untuk identifikasi kontras densitas ke arah vertikal dan horisontal, diantarnya konfigurasi Wenner mapping, dipole-dipole, pole-pole.

\section{Konfigurasi Wenner}

Konfigurasi Wenner merupakan salah satu konfigurasi yang sering digunakan dalam eksplorasi geolistrik, dengan susunan jarak antar elektroda sama panjang. Kelebihan dari konfigurasi ini adalah pada pengambilan data, mampu memperoleh data yang teliti dibandingkan dengan konfigurasi lainnya ${ }^{[17]}$. Konfigurasi ini terdiri dari 2 (dua) elektroda arus dan 2 elektroda potensial. Elektroda potensial ditempatkan pada bagian dalam dan elektroda arus dibagian luar (gambar 3.) dengan jarak antar elektroda sebesar $a^{[18]}$. Pengukuran dilakukan dengan memindahkan semua elektroda secara bersamaan dengan jarak $n a$ selalu sama $(\mathrm{AM}=\mathrm{MN}=\mathrm{AB})$. Konfigurasi ini digunakan dalam pengambilan data secara lateral atau mapping. Faktor geometris untuk konfigurasi ini sebesar $2 \pi a$, sehingga besar resisitivitas semu adalah

$$
\rho=2 \pi a\left(\frac{V}{I}\right)
$$

Keunggulan lainnya dari konfigurasi Wenner ini adalah ketelitian pembacaan tegangan pada elektroda $\mathrm{MN}$ lebih baik dengan angka yang relatif besar karena elektroda MN yang relatif dekat dengan elektroda $\mathrm{AB}$. Adapun pemasangan elektrode konfigurasi wenner seperti gambar 3. dibawah ini.

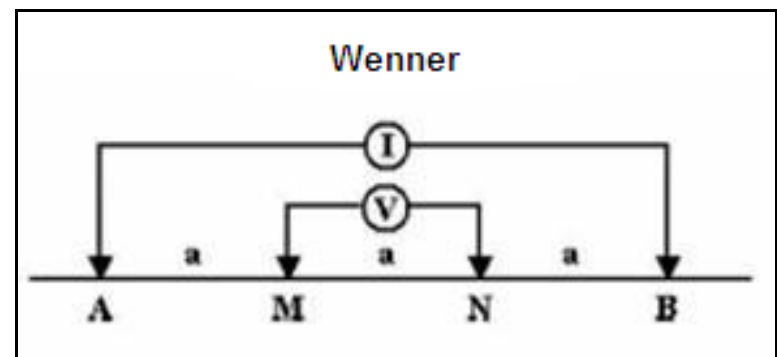

Gambar 3. Skema pemasangan elektroda konfigurasi Wenner ${ }^{[18]}$ 


\title{
METODE
}

Prosedur awal sebelum melakukan akuisisi data metode geolistrik resisitivitas Wenner adalah membuat desain survei. Sebagaimana yang telah dijelaskan pada bab sebelumnya, bentuk dari desain survei metode resistivitas ini berupa lintasan dengan panjang tertentu. Lintasan tersebut dapat saling memotong agar dalam tahap interpretasi, data-data per lintasan tersebut akan mudah dikorelasikan satu lintasan dengan lintasan yang lain. Metode resistivitas ini menggunakan beberapa peralatan survei, antara lain : resisvitimeter OYYO MCOHM, elektroda 2 (dua) pasang, baterai ACCU, Multimeter.

\begin{abstract}
Akuisisi Data
Pengukuran dengan metode wenner dilakukan di area taman candi dengan membuat empat lintasan sebagaimana tertera dalam gambar 1. (b) diatas. Pengaturan pemindahan untuk konfigurasi Wenner mengikuti Gambar 3. diatas dimana jarak antar elektroda aruspotensial atau potensial-potensial harus sama. Sebagai catatan untuk jarak titik datum tidak perlu sama dengan jarak elektroda. Penyerderhanaan yang dilakukan adalah dengan menggeser terus menerus dengan jarak spasi $a$ elektroda potensial hingga ke ujung datum yang sudah ditentukan. Jika sepasang elektroda potensial tersebut telah mencapai ujung lintasan pengukuran maka elektroda arus digeser sejauh a dari elektroda arus terluar. Setiap kali pemindahan jarak antar elektroda arus adalah $a$. Sedangkan spasi antara elektroda arus dan potensial bagian dalam adalah $n a$. Kemudian catat data hasil dilapangan pada microsoft exel selanjutanya data resist terlebih dahulu dikalikan dengan faktor geometri konfigurasi wenner untuk mendapatkan nilai resistivitas $(\rho)$ bawah permukaan di daerah Candi Badut.
\end{abstract}

\section{Pengolahan Data Resistivitas Wenner}

Konfigurasi wenner merupakan metode resistivitas mapping yang bekerja diwilayah secara horisontal dan vertikal bersama-sama. Sehingga dapat dipastikan hasil dari pengukuran berupa penampang lateral vertikal secara 2 (dua) dimensi. Pengolahan data kedua konfigurasi ini menggunakan software RES2dinv, dimana data tersebut akan diplot sesuai posisi datum saat akuisisi. Hasil pengolahan tersebut diperoleh distribusi nilai resistivitas $(\rho)$ bawah permukaan tanah berupa citra warna. Citra warna yang terdapat pada kontur setiap lintasan didefinisikan berdasarkan nilai resistivitas $(\rho)$. Adapun nilai resistivitas beberapa batuan adalah Tanah lempung (basah, lembab) $1.5 \Omega \mathrm{m}-3.0 \Omega \mathrm{m}$, tanah lanau dan tanah lanau basah lembek $3 \Omega \mathrm{m}-15 \Omega \mathrm{m}$, Tanah lanau, pasiran $15 \Omega \mathrm{m}-$ $150 \Omega \mathrm{m}$, batuan dasar berkekar terisi tanah lembab $150 \Omega \mathrm{m}-300 \Omega \mathrm{m}{ }^{[19]}$. Pada data penelitian lainnya didapatkan nilai resistivitas batuan andesit $40 \Omega \mathrm{m}<\rho<250 \Omega \mathrm{m}^{[7]}$.

\section{Interpretasi Kualitatif dan Kuantitatif}

Pada proses ini peneliti melakukan interpretasi hasil pengolahan data, kemudian mengkorelasikannya dengan peta geologi lokal atau data sumur secara kualitatif. Sebelum mengkorelasikan dengan data-data pendukung tersebut terlebih dahulu, hasil pengolahan disingkronisasi dengan data resistivitas acuan secara kuantitatif.

\section{HASIL DAN PEMBAHASAN}

Akuisisi data pada setiap lintasan sepanjang 48 meter, spasi 2 meter, dengan variasi jarak antara elektroda berturut-turut adalah $2 \mathrm{~m}, 4 \mathrm{~m}, 6 \mathrm{~m}, 8 \mathrm{~m}$ sampai $48 \mathrm{~m}$. Hasil penelitian kali ini didapatkan informasi nilai resitivitas batuan dari kedalaman 0,5m-7,91m, dengan mengasumsikan pondasi candi terdapat pada kedalaman $0,5 \mathrm{~m}-1,5 \mathrm{~m}$ dan kedalaman $1,51 \mathrm{~m}-$ 7,91m memberikan informasi struktur lapisan tanah. 
Akuisisi data pada lintasan 1 dimulai dari koordinat $7^{\circ} 57^{\prime} 27.70^{\prime \prime} \mathrm{LS}$ dan $112^{\circ} 35^{\prime} 55.71^{\prime \prime} \mathrm{BT}$ dan diakhiri pada koordinat $7^{\circ} 57^{\prime} 27.16^{\prime \prime}$ LS dan $112^{\circ} 35^{\prime} 54.22 " B T$. Pada kedalaman 0,05m-1,5m yang diberi kotak hitam garis putus-putus pada Gambar 4. dibawah, nilai resistivitas batuannya adalah $14,5970 \Omega \mathrm{m}-36,7183 \Omega \mathrm{m}$, dimana batuan yang memiliki nilai resisitivitas kisaran $36,7183 \Omega \mathrm{m}$ diasumsikan sebagai batuan pondasi candi (andesit) yang ditunjukkan warna merah pekat dengan nilai resistivitas terbesar diarea tersebut. Pada kedalaman 1,51m-7,91 m nilai resistivitas batuan adalah 9,88 $\Omega \mathrm{m}-25,2066 \Omega \mathrm{m}$ dan jenis material pada kedalaman tersebut adalah tanah lanau basah lembek untuk resistivitas kurang dari $15 \Omega \mathrm{m}$ dan tanah lanau, pasiran untuk resistivitas lebih dari $15 \Omega \mathrm{m}$.

Akuisisi data pada lintasan 2 dimulai dari koordinat $7^{0} 57^{\prime} 28,44^{\prime \prime}$ LS dan $112^{0} 35^{\prime} 56,38^{\prime \prime}$ BT, dan diakhiri pada koordinat $7^{0} 57^{\prime} 47,69^{\prime \prime}$ Ls dan $112^{0} 35^{\prime} 53,05^{\prime \prime}$ BT. Pada kedalaman 0,05m-1,5m yang diberi kotak hitam garis putus-putus pada Gambar 5. dibawah, nilai resistivitas batuannya adalah $17,14 \Omega \mathrm{m}-66,8 \Omega \mathrm{m}$, dimana batuan yang memiliki nilai resisitivitas kisaran $66,8 \Omega \mathrm{m}$ diasumsikan sebagai batuan pondasi candi (andesit) yang ditunjukkan warna merah pekat dengan nilai resistivitas terbesar diarea tersebut. Pada kedalaman 1,51m-7,91 m nilai resistivitas batuan adalah $12,38 \Omega \mathrm{m}-26,41 \Omega \mathrm{m}$ dan jenis material pada kedalaman tersebut adalah tanah lanau basah lembek dan tanah lanau, pasiran.

Akuisisi data pada lintasan 3 dimulai dari koordinat $7^{\circ} 57^{\prime} 28.70$ "LS dan $112^{0} 35^{\prime} 54,25^{\prime \prime} \mathrm{BT}$, dan diakhiri pada koordinat $7^{\circ} 57^{\prime} 28.27^{\prime \prime L S}$ dan $112^{\circ} 35^{\prime} 55,67^{\prime \prime}$ BT. Pada kedalaman 0,05m-1,5m yang diberi kotak hitam garis putus-putus pada Gambar 6. dibawah, nilai resistivitas batuannya adalah $17,57 \Omega \mathrm{m}-33,87 \Omega \mathrm{m}$, dimana batuan yang memiliki nilai resisitivitas kisaran 33,87 $\Omega \mathrm{m}$ diasumsikan sebagai batuan pondasi candi (andesit) yang ditunjukkan warna merah pekat dengan nilai resistivitas terbesar diarea tersebut. Pada kedalaman 1,51m-7,91 m nilai resistivitas batuan adalah 7,36 $\Omega \mathrm{m}-20,76 \Omega \mathrm{m}$ dan jenis material pada kedalaman tersebut adalah tanah lanau basah lembek dan tanah lanau, pasiran.

Akuisisi data pada lintasan 4 diawali pada koordinat $7^{\circ} 57^{\prime} 28.48^{\prime \prime} L S$ dan $112^{\circ} 35^{\prime} 53.93$ "BT dan di akhiri pada koordinat $7^{\circ} 57^{\prime} 26.77^{\prime \prime} L S$ dan $112^{\circ} 35^{\prime} 54.63^{\prime \prime}$ BT. Pada kedalaman 0,05m-1,5m yang diberi kotak hitam garis putus-putus pada Gambar 7. dibawah, nilai resistivitas batuannya adalah $11,57 \Omega \mathrm{m}-37,19 \Omega \mathrm{m}$, dimana batuan yang memiliki nilai resisitivitas kisaran 37,19 $\Omega \mathrm{m}$ diasumsikan sebagai batuan pondasi candi (andesit) yang ditunjukkan warna merah pekat dengan nilai resistivitas terbesar diarea tersebut. Pada kedalaman 1,51-7,91 m nilai resistivitas batuan adalah 9,24 $\Omega \mathrm{m}-20,76 \Omega \mathrm{m}$ dan jenis material pada kedalaman tersebut adalah tanah lanau basah lembek dan tanah lanau, pasiran.

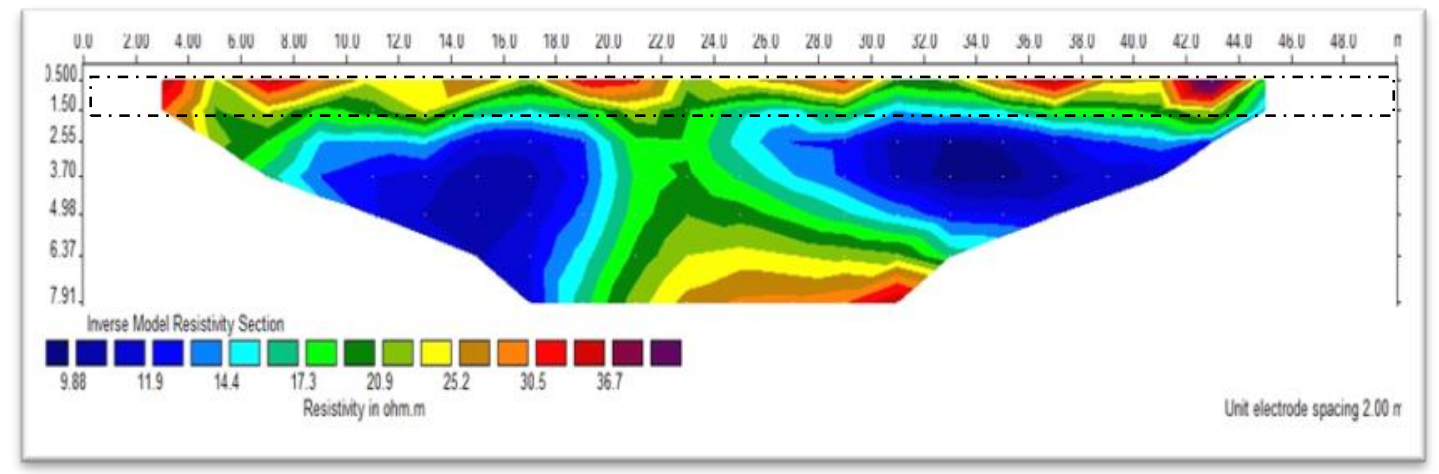

Gambar 4. Kontur resistivitas ( $\rho$ ) pada lintasan 1 


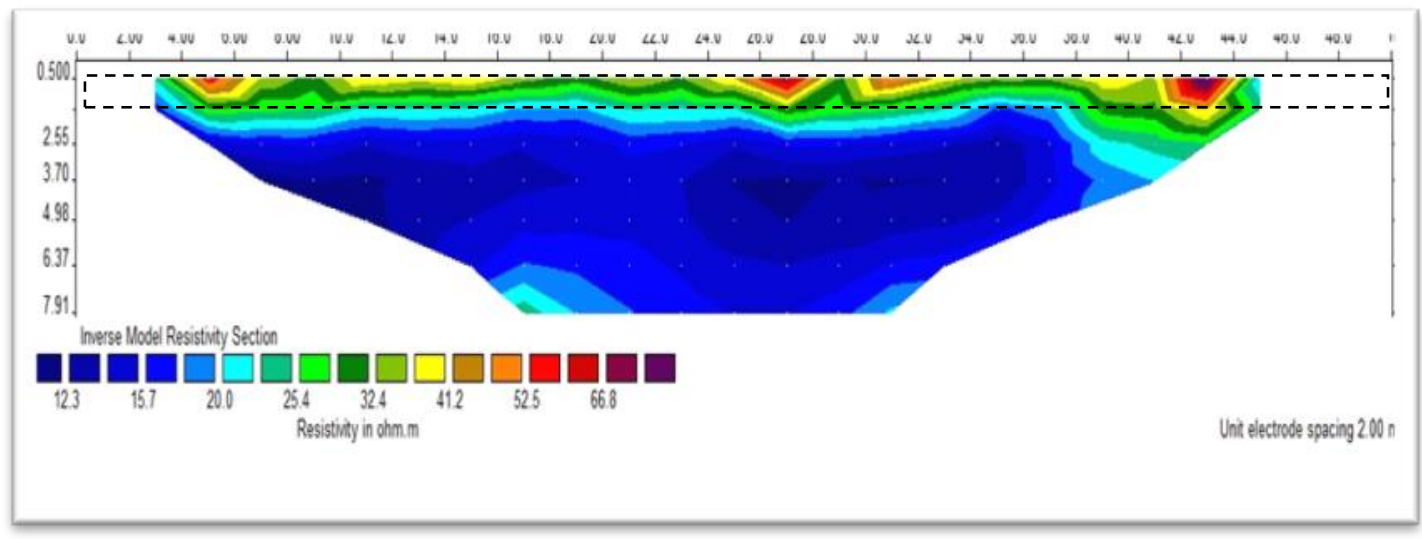

Gambar 5. Kontur resistivitas ( $\rho$ ) pada lintasan 2

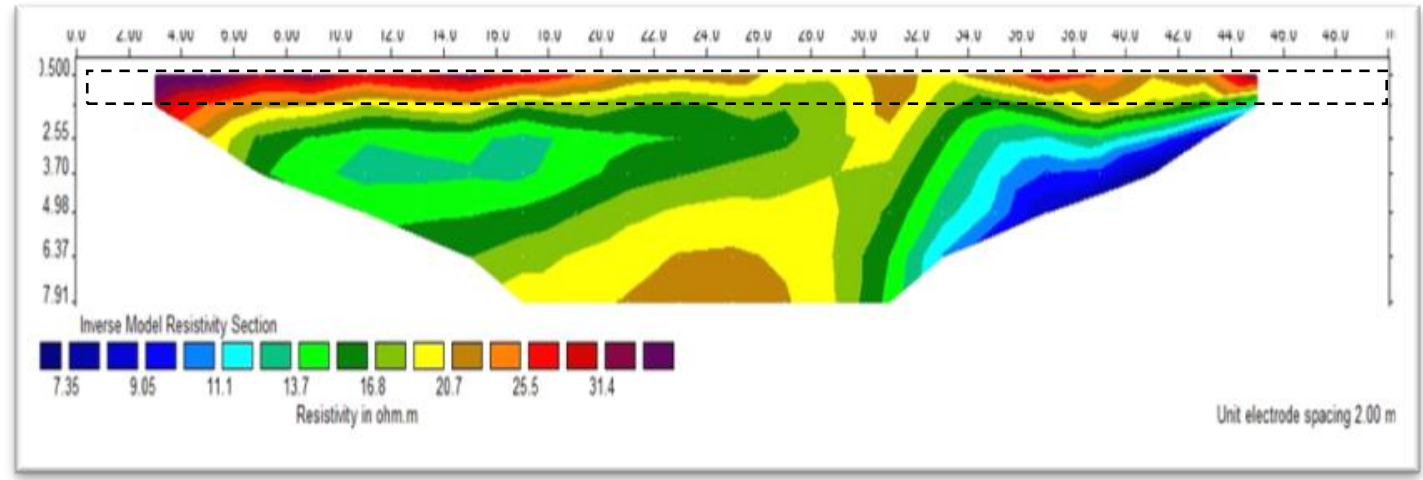

Gambar 6. Kontur resistivitas ( $\rho$ ) pada lintasan 3

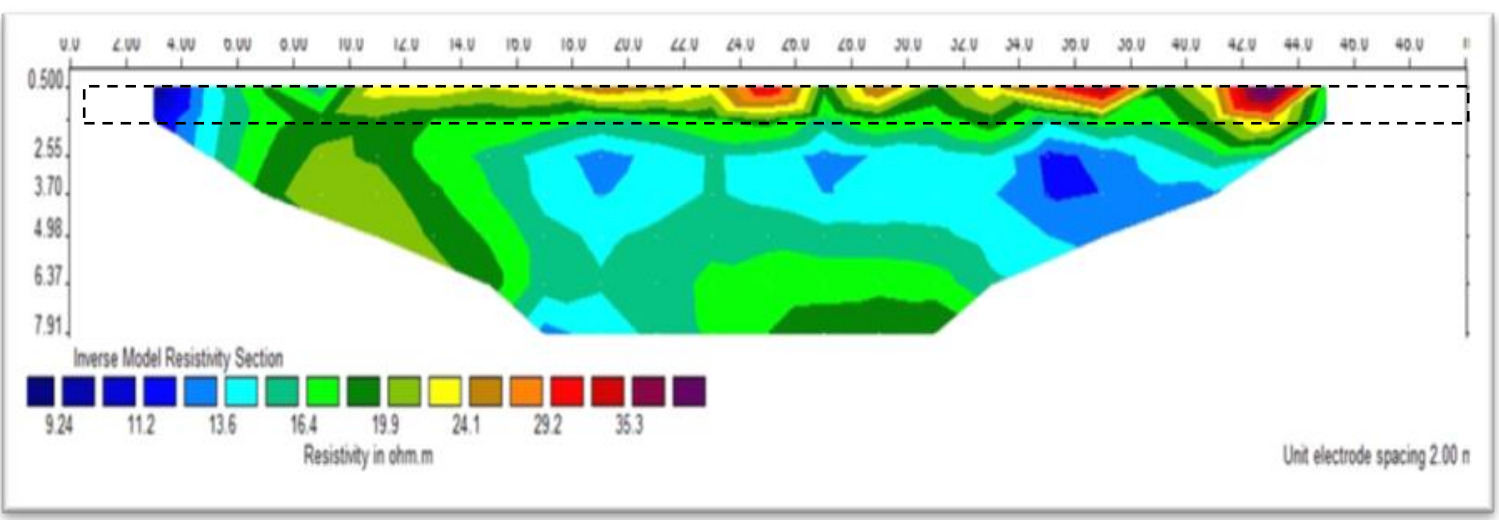

Gambar 7. Kontur resistivitas ( $\rho$ ) pada lintasan 4

\section{KESIMPULAN}

Berdasarkan hasil keseluruhan interpolasi lintasan 1,2,3 dan 4 dengan metode geolistrik resistivitas konfigurasi wenner dapat diketahui bahwa batuan pondasi candi (andesit) berada pada kedalaman $0,5 \mathrm{~m}-1,5 \mathrm{~m}$ yang merupakan batuan dengan nilai resistivitas terbesar dibandingkan batuan yang lainnya, dengan nilai resistivitas batuan (andesit) kisaran antara 33,87 $\Omega \mathrm{m}-66,8 \Omega \mathrm{m}$, sedangkan pada kedalaman $1,51 \mathrm{~m}-7,91 \mathrm{~m}$ terdiri dari tanah lanau basah lembek dan tanah lanau, pasiran, tidak ditemukan batuan candi (andesit) yang terkubur didalam tanah. 


\section{DAFTAR PUSTAKA}

1 Candi badut, Destinasi Wisata situs sejarah. (2015). Retrieved (maret 16, 2018) from candi badut, destinasi Wisata situs sejarah:

https://www.cendananews.com/2015/03/candi-badut-destinasi-wisata-situssejarah.html

2 Blatt, Harvey, dan Robert JT. 1996. Petrology. Freeman. Isbn 0-7167-2438-3.

3 Bakrum dkk.2003. Penyelidikan Terpadu Daerah Panas Bumi Oka, Kabupeten Flores Timur, NTT, in Kolokium Hasil Kegiatan Inventarisasi Sumber Daya Mineral DIM, Bandung: Badan Geologi Pusat Sumber Daya Mineral Batubara dan Panas Bumi, pp. 33.1-33.8.

4 Pasha, D. A. 2015.Karakterisasi Batuan Intrusi Sekitar Gunung Api Slamet Berdasarkan Analisis Petrografi, Unsur Utama, dan Unsur Jejak Daerah Baturraden dan Sekitarnya, Kabupaten Banyumas, Provinsi Jawa Tengah," in Proc. Sem. Nas. Kebumian Ke-8 Academia-Industry Linkage 15-16, Grha Sabha Pramana, Yogyakarta: Universitas Gadjah Mada, pp. 824-834, 2015.

5 Putra, ART dan Agus R. 2019. Perhitungan Volume Cadangan Bahan Galian Tambang Andesit Menggunakan Metode Resistivitas Dipol-Dipol dan Interpolasi 3D di Lapangan "A", Prosiding Seminar Nasional Fisika (E-Journal) SNF2019, pe-ISSN: 2476 ISSN: 2339- -0654 939, DOI:doi.org/10.21009/03.SNF2019.02.PA.11

6 Jayadi, H, dkk. 2019. Identifying Andesite Rocks Sources Using Geoelectrical Resistivity in Loli, Donggala Regency, Central Sulawesi, Journal of Physical Science and Engineering, Vol. 4, No. 2, 2019, Page 45-54, DOI: 10.17977/um024v4i22019p045, EISSN: 2541-2485.

7 Munaji, Imam, S dan Lutfinur,I,. 2013. Penentuan Tahanan Jenis Batuan Andesit Menggunakan Metode Geolistrik Konfigurasi Schlumberger (Studi Kasus Desa Polosiri). Jurnal Fisika,Vol. 3 No. 2.

8 Sunarya, W, Hasanuddin, syamsuddin, maria, erfan. 2017. Identifikasi Bijih Besi (Fe) Menggunakan Metoda Geolistrik Resistivitas Konfigurasi Wenner schlumberger Di Kabupaten Luwu. Jurnal Geocelebes Vol. 1 No. 2, 72 - 81, ISSN : 2579-5821 (Cetak) ISSN : 2579-5546 (Online) Alamat URL : http://journal.unhas.ac.id/index.php/geocelebes

9 Armada, I Wayan, Titi Hapsari. 2015. Petrogenesis Dan Proses Pelapukan Batuan Penyusun Candi Prambanan Berdasarkan Analisis Petrografi Dan Geokimia, Proceeding, Seminar Nasional Kebumian Ke-8 Academia-Industry Linkage 15-16 Grha Sabha Pramana 756, Yogyakarta: Universitas Gadjah Mada.

10 Widodo, S, dkk.,2013, Identifikasi Sebaran Kandungan Bijih Besi Di Kabupaten Bengkayang Menggunakan Metode Geolistrik Resistivitas. Prisma Fisika, Vol.1 No.1, 14-21

11 Ojo, J.S., Olorunfemi, M.O., Akintorinwa1, O.J., Bayode1, S., Omosuyi, G.O. and Akinluyi, F.O. 2015. Subsoil competence characterization of the Akure metropolis, southwest Nigeria. Journal of Geography, Environment and Earth Science International, Vol. 3 No. 1, pp. 1-14, Article no.JGEESI.15851

12 Susilo, A, Sunaryo, Fina ,F dan Sarjiyana, 2018. Fault Analysis In Pohgajih Village, Blitar, Indonesia Using Resistivity Method For Hazard Risk Reduction. International Journal of GEOMATE, Jan., 2018 Vol.14, Issue 41, pp.111-118 Geotec., Const. Mat. \& Env. ISSN: 2186-2982 (Print), 2186-2990 (Online), Japan. DOI: https://doi.org/10.21660/2018.41.87552

13 Islami, N. 2011. Geoelectrical Resistivity Method For Salt/Brackish Water Mapping. Journal of Coastal Development Volume 14, No. 2, 104-114, ISSN : 1410-5217 Accredited : 83/Dikti/Kep/2009 
14 Telford, W.M., L.P. Geldart, R.E. Sheriff. 1990. Applied Geophysics, $2^{\text {nd }}$ Edition, Cambridge University.

15 Loke, M.H. 2007. Rapid 2-D Resistivity \& IP inversion using the least-squares method, Geoelectrical Imaging 2D and 3D, GEOTOMO SOFTWARE, Malaysia

16 Hendrajaya, L., dan Arif, I. 1990. Geolistrik Tahanan Jenis, Laboratorium Fisika Bumi, Jurusan FMIPA, ITB. Bandung.

17 Saputro, H \& Puji, H, W. 2017. Penyebaran Batuan Andesit Dengan Metode Geolistrik di Desa Laksanamekar Bandung, Jawa Barat, KURVATEK Vol.2 . No. 1, April 2017, pp.31-37 ISSN: 2477-7870,

18 Kurniati, Asih dkk. 2008. Buku Panduan : Workshop Geofisika. Laboratorium Geofisika, Jurusan Fisika, Fakultas MIPA, Universitas Brawijaya. Malang.

19 Roy, E. 2005. Geotechnical Engineering Investigation Hand Book second edition. Taylor \& Francis Group. New York 